\title{
Risk factors for failure of revision total hip arthroplasty using a Kerboull-type acetabular reinforcement device
}

\author{
Shinya Hayashi ${ }^{1 *}$, Takayuki Nishiyama², Shingo Hashimoto', Tomoyuki Matsumoto', Koji Takayama',
}

Kazunari Ishida ${ }^{3}$, Kotaro Nishida ${ }^{1}$ and Ryosuke Kuroda ${ }^{1}$

\begin{abstract}
Background: The present study aimed to identify the risk factors associated with revision total hip arthroplasty (THA) failure using a Kerboull-type (KT) plate.

Methods: We analyzed 77 revision THAs using cemented acetabular components with a KT plate for aseptic loosening between May 2000 and March 2012. We examined the association of bone graft type, acetabular bone defects, age at the time of surgery, preoperative Japanese Orthopaedic Association (JOA) score, postoperative JOA hip score, and body mass index, with radiographic failure as the outcome.

Results: The 7.4-year radiographic failure survival rate was $81.6 \%$. The survival rate was significantly different between the beta-tricalcium phosphate ( $\beta$-TCP) group and the bulk allograft group $(p=0.019)$. The survival curves were also significantly different between the $\beta$-TCP group and bulk allograft group $(p=0.036)$. American Academy of Orthopaedic Surgeons type IV was significantly associated with radiographic failure (odds ratio [OR]: 15.5, 95\% confidence interval [Cl]: 1.4-175.4; $p=0.032$ ).
\end{abstract}

Conclusions: The midterm outcomes of revision THA indicate that type of bone graft and bone defect size may affect radiographic survival rate when using a KT plate.

Keywords: Revision total hip arthroplasty, KT plate, Allograft, Beta-tricalcium phosphate, Hydroxyapatite

\section{Background}

Outcomes following THA have improved owing to advancements in prostheses and surgical procedures [1-3]. However, failure of acetabular components can lead to large bone defects with residual bone loss. It is well documented that bone defects determine outcome and management after revision hip surgery [4].

To compensate for large bone loss, prosthetic augmentation with bone grafting was developed, and several types of reinforcement devices are currently in use for revision THA, including the Burch-Schneider anti-protrusion cage [5], Mueller support ring [6], Ganz reinforcement ring [7], Kerboull device $[8,9]$, and Kerboull-type (KT) device $[10,11]$ (Table 1).

\footnotetext{
* Correspondence: s11793290@yahoo.co.jp

${ }^{1}$ Department of Orthopaedic Surgery, Kobe University Graduate School of

Medicine, 7-5-1 Kusunoki-cho, Chuo-ku, Kobe 650-0017, Japan

Full list of author information is available at the end of the article
}

The use of a Kerboull reinforcement device can reduce excessive bone graft loading during incorporation and remodeling processes [12, 13]. The KT plate, a modified Kerboull plate made of titanium with a similar shape, has various offsets and vertical lengths (Fig. 1). Therefore, it is particularly useful for treating severe dysplasia or large bone defects of the acetabulum. Since 2000, we have used the KT plate with artificial bone materials or bulk grafts fashioned from a femoral head allograft.

Bone graft substitutes in combination with or without human bone are widely used for reconstruction of massive acetabular bone defects in revision surgery [13-16]. Good results have been associated with bone graft substitutes for acetabular bone defects [13-16] (Table 2).

Factors such as bone defect size, bone graft, age, and postoperative activity level may affect implant survival 
Table 1 Results of previous studies

\begin{tabular}{llllll}
\hline Authors & Device type & Cases & Bone defect classification & Mean f/u years & Survival rate (loosening endpoint) \\
\hline Ilyas et al. [5] & Burch-Schneider cage & 33 & AAOS III, IV & $6.2 y$ & $85 \%$ \\
Schlegel et al. [6] & Mueller reinforcement ring & 164 & AAOS I-IV & 8 y & $95 \%$ \\
Kerboull et al. [8] & Kerboull reinforcement device & 53 & AAOS III-IV & $13 y$ & $92.1 \%$ \\
Kawanabe et al. [9] & Kerboull reinforcement device & 42 & AAOS II-IV & $8.7 y$ & $67 \%$ \\
Baba et al. [10] & KT-plate & 18 & AAOS II, III & $5 y$ & $87.5 \%$ \\
Hori et al. [11] & KT-plate & 32 & AAOS III, IV & $10 y$ & $82.1 \%$ \\
\hline
\end{tabular}

following revision THA, but no study has identified the critical risk factors for failure of revision THA using a KT plate. We hypothesized that factors specific to patient status or bone grafting may be predictive of poorer radiographic outcomes after revision THA. Therefore, the aim of this study was to evaluate the association between survival rates for radiological loosening and results according to bone defect or type of graft. Factors such as age and postoperative activity level were also considered.

\section{Clinical relevance}

- Unlike prior reports, our study analyzed predictive factors for radiographic failure after revision THA.

\section{Methods}

\section{Patients and surgery}

A total of 95 consecutive revision THAs (86 patients) for aseptic loosening using cemented acetabular components with a KT acetabular reinforcement device (KT plate; KYOCERA Medical Corporation, Kyoto, Japan) were performed between May 2000 and March 2012. Exclusion criteria were recurrent dislocations and revision due to infection ( 8 cases); 10 cases were excluded because of loss to follow-up. Therefore, the data from 77 hips (6 men and 71 women) were included in the analysis. Initial diagnoses comprised osteoarthritis (59 hips), idiopathic osteonecrosis of the femoral head (4 hips), and rheumatoid arthritis (14 hips) (Fig. 1). Thirty-one patients underwent both acetabular- and femur-side revision surgery (cemented stem: 11 patients; cementless-stem: 20 patients), and 46 patients underwent only acetabular-side surgery (Fig. 3). The KT plate is available with an inside dome diameter of $44 \mathrm{~mm}, 48 \mathrm{~mm}$, or $52 \mathrm{~mm}$, and a vertical offset of $+0 \mathrm{~mm},+10 \mathrm{~mm}$, or $+15 \mathrm{~mm}$. We used the 44-mm model in 20 patients, the $48-\mathrm{mm}$ model in 35 patients, and the 52-mm model in 22 patients; we used the +0 -mm vertical offset in 37 patients, the +10 -mm vertical offset in 31 patients, and the +15 -mm vertical offset in 9 patients. The inner head size diameter was $28 \mathrm{~mm}$ or $32 \mathrm{~mm}$. We used an inner head size of $28 \mathrm{~mm}$ in 43 patients and $32 \mathrm{~mm}$ in 34 patients (Fig. 3 ).

Surgeries were performed using a direct lateral approach. All surgeries were performed by three experienced senior surgeons. The degree of acetabular bone defect was assessed after removal of the loosened implant, and the acetabular bone defect was augmented with a bone graft. The KT plate was fixed firmly by an inferior hook to the teardrop and a superior flange with at least two screws to the ilium. The polyethylene component was then cemented into the dome of the plate. When fixation of the inferior hook to the teardrop was not possible due to loss of host bone, the inferior hook of the $\mathrm{KT}$ plate was fixed to the ischium, inferior acetabular dome, or allograft. Between May 2000 and February 2003, bone defects were filled with $\beta$-TCP granules (OSferion; Olympus, Tokyo, Japan). Between February 2003 and March 2009, the bone defect was filled with HA block (Osteograft, Apaceram; KYOCERA Medical Corporation, Kyoto, Japan). Since 2009, we have used femoral head allografts that were harvested under sterile conditions and stored at $-80{ }^{\circ} \mathrm{C}$. After removing the remaining cartilage and soft tissue, the femoral head was cut using an oscillating saw into an appropriate shape and size to be used as a bulk allograft. A representative case with preoperative and postoperative $\mathrm{X}$-rays is shown in Fig. 2. Postoperatively, full weight-bearing

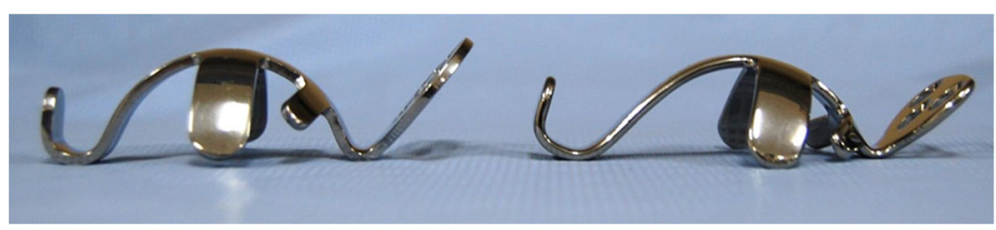

Fig. 1 Photographs of the KT plate in the original position (left) and high placement position (right) 
Table 2 Results of previous studies

\begin{tabular}{|c|c|c|c|c|c|}
\hline Authors & Type of graft & Cases & $\begin{array}{l}\text { Bone defect } \\
\text { classification }\end{array}$ & $\begin{array}{l}\text { Mean f/u } \\
\text { duration }\end{array}$ & $\begin{array}{l}\text { Survival rate (loosening } \\
\text { endpoint) }\end{array}$ \\
\hline McNamara et al. [13] & allograft and hydroxyapatite & 37 & AAOS I-III & $56.9 m$ & $95 \%$ \\
\hline Oonishi et al. [14] & hydroxyapatite & 40 & AAOS I-II & $4-10 y$ & $93 \%$ \\
\hline Schwartz et al. [15] & biphasic calcium phosphate ceramics & 29 & Data not specified & more than $6 \mathrm{~m}$ & $100 \%$ \\
\hline Blom et al. [16] & allograft and tricalcium phosphate-hydroxyapatite & 43 & Data not specified & $24 m$ & $98 \%$ \\
\hline
\end{tabular}

was tolerated by all patients within 3 days of surgery and patients were discharged from the hospital with a T-cane gait at 3 weeks postoperatively. The weightbearing protocol was not changed over the course of the study period. All data were obtained in accordance with the World Medical Association Declaration of Helsinki Ethical Principles for Medical Research Involving Human Subjects.

\section{Postoperative evaluation}

Hip function was evaluated using the Japanese Orthopaedic Association (JOA) score, which allocates 40 points for pain, 20 points for range of motion, 20 points for walking ability, and 20 points for activities of daily living, with a maximum total score of 100 points [17]. The JOA score was evaluated preoperatively and at the final follow-up assessment. Body mass index (BMI) and University of California, Los Angeles (UCLA) activity scores were also evaluated at the final follow-up assessment. Acetabular defects were classified by one senior experienced surgeon according to the American Academy of Orthopedic Surgeons (AAOS) grading system [11]. Type II

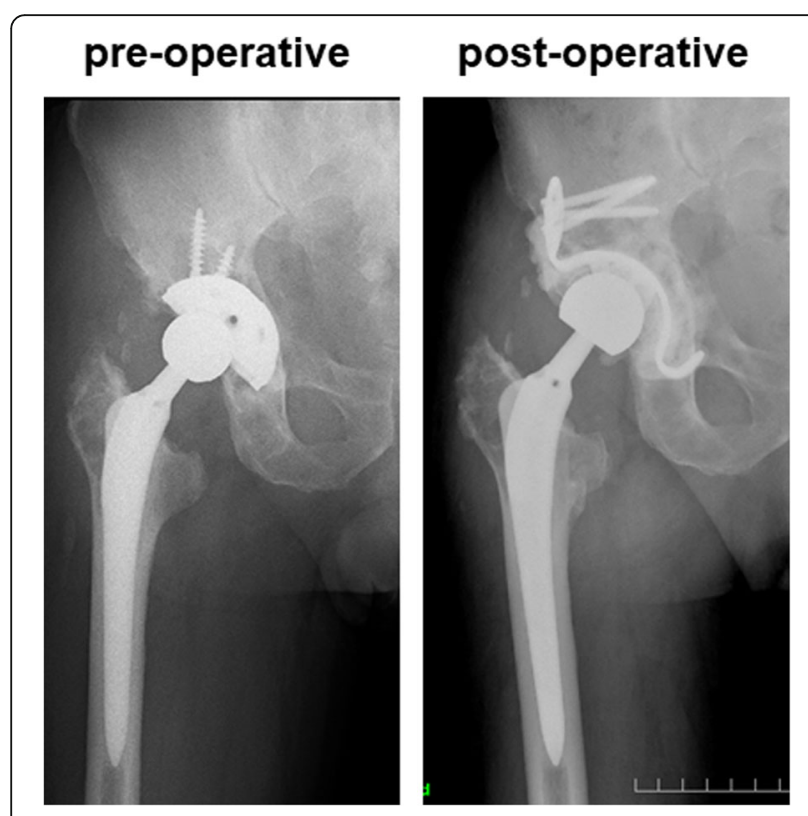

Fig. 2 Representative case of preoperative and postoperative X-rays defects (cavitary bone loss) were found in 6 hips (7.8\%), type III defects (cavitary and segmental bone loss) in 66 hips (85.7\%), and type IV defects (pelvic discontinuity) in 5 hips (6.5\%) (Fig. 3).

Radiological failure was defined by any of the following three criteria, according to Kawanabe [9]: 1 . substantial migration defined as a change in the inclination angle of greater than $3^{\circ}$ or migration greater than 2 to $3 \mathrm{~mm}$; 2. progressive radiolucent line greater than $2 \mathrm{~mm}$ wide in all three zones as defined by DeLee and Charnley [18]; or 3. breakage of screws or device without migration or change in inclination. The postoperative and final follow-up radiographs were compared to assess radiological failure of the implant. The failure rate may be affected by the follow-up duration. Therefore, we performed survivorship analysis using radiographic failure as the endpoint.

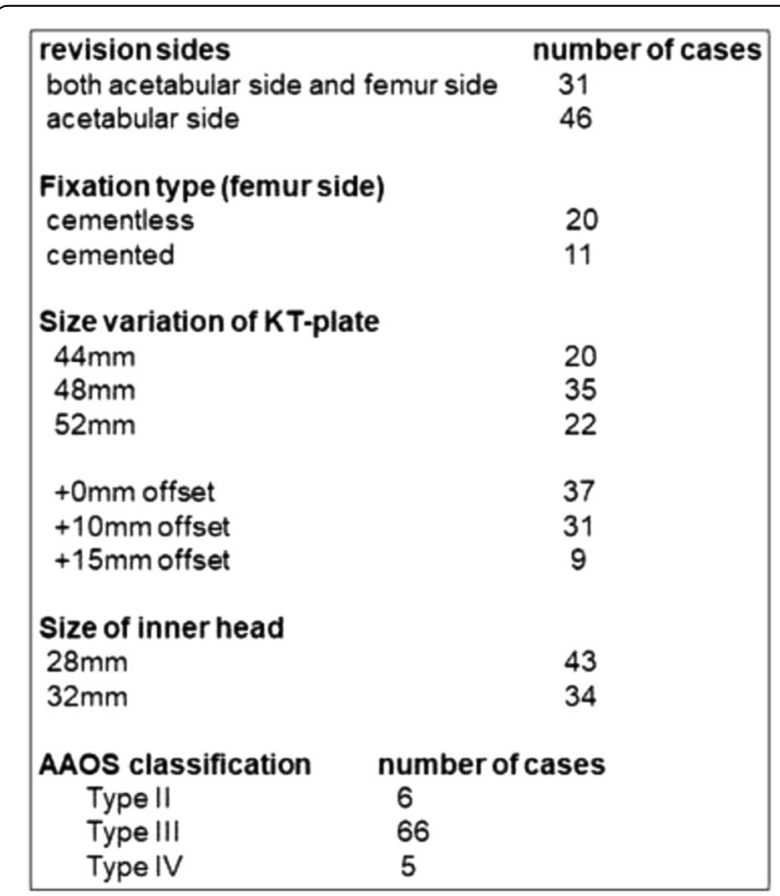

Fig. 3 Summary of revision THA and number of patients according to AAOS classification. AAOS: American Academy of Orthopaedic Surgeons 


\section{Statistical analysis}

Demographic data were recorded as the mean \pm standard deviation (SD) unless otherwise indicated. All data were normally distributed. Statistical analysis was performed using one-way analysis of variance with the Tukey post hoc test for multiple comparisons of paired samples. Cumulative probabilities of radiographic failure rate were estimated by using the Kaplan-Meier method. The survivorship curves for various subgroups were compared using the log-rank test. Logistic regression was performed to examine the association of age at the time of the operation, preoperative JOA score, postoperative JOA score, BMI, UCLA activity score, and AAOS classification with radiographic failure. Odds ratios (ORs) and $95 \%$ confidence interval (CIs) were calculated. Multivariate analysis was performed to adjust for potential confounders of age at the time of operation, preoperative JOA score, postoperative JOA score, BMI, UCLA activity score, and AAOS classification. The database was analyzed using SPSS software (IBM Corp., Armonk, NY, USA). Values of $p<0.05$ were considered significant.

\section{Results}

\section{Patient background}

This study is a retrospective review of patient records. The patient background is shown in Fig. 4. The JOA score at the final follow-up examination increased significantly $(p<0.001)$. The patient background including pre- and postoperative JOA score, BMI, and UCLA

\begin{tabular}{|c|c|}
\hline number of cases & 77 \\
\hline $\operatorname{sex}$ & male 6 , female 71 \\
\hline age & $66.6 \pm 10.4$ у.о. \\
\hline preoperative & \\
\hline $\begin{array}{l}\text { JOA score } \\
\text { postoperative }\end{array}$ & $53.5 \pm 16.0$ points \\
\hline JOA score & $69.2 \pm 13.6$ points \\
\hline BMI & $22.4 \pm 4.0 \mathrm{~kg} / \mathrm{mm}^{2}$ \\
\hline $\begin{array}{l}\text { UCLA score } \\
\text { at final follow-up }\end{array}$ & $4.2 \pm 1.5$ points \\
\hline Follow-up duration & $7.4 \pm 4.1$ yrs \\
\hline
\end{tabular}

Fig. 4 Patient demographic data. JOA: Japanese Orthopaedic Association, THA: total hip arthroplasty, BMl: body mass index, UCLA; University of California, Los Angeles score at final follow-up were not significantly changed according to the bone defect type or type of bone graft.

\section{Radiographic survival rate}

Radiographic failure was evaluated for revision THA with $\beta$-TCP, hydroxyapatite (HA), and bulk allografts using cemented sockets with a KT plate. The total survival rate was $81.6 \%$. The survival rate was $74.2 \%$ in the $\beta$-TCP group, $81.5 \%$ in the HA group, and $94.7 \%$ in the bulk allograft group (Fig. 5). However, the survival rate in the $\beta$-TCP group was significantly lower than in the HA $(p=0.048)$ or bulk allograft groups $(p=0.019)$. We also evaluated the stability of the acetabular component using the AAOS classification. The survival rate was $100 \%$ in the AAOS type II group, $83.3 \%$ in the type III group, and $40 \%$ in the type IV group (Fig. 5). The survival rate in the AAOS type IV group was significantly lower than in the type III group $(p=0.033)$.

We further performed survivorship analysis using radiographic failure as the endpoint. The survival curves were significantly different between the $\beta$-TCP group and bulk allograft group $(p=0.036)$, but were not significantly different between the HA group and bulk allograft group (Fig. 6).

\section{Risk factors for radiographic failure}

To identify risk factors for radiographic failure, we performed multivariate analysis to test the association of AAOS classification, clinical factors including age, pre- and postoperative JOA scores, BMI, UCLA activity score, and follow-up duration with radiographic failure and revision. AAOS type IV defect was found to be a risk factor for radiographic failure (OR: 15.5, 95\% CI: 1.4-175.4, $p=0.032$ ).

\section{Discussion}

The core evaluation in this study focuses on the relationship between survival rates for radiological loosening and results according to bone defect or type of graft. We demonstrated that the 7.4-year survival rate was $81.6 \%$ when radiographic failure was the endpoint. These results are similar to those reported by previous studies [9-11].

Various types of graft have been used for reconstruction of acetabular bone defects. Blom et al. reported a 2-year survival rate of $100 \%$ in revision THA with impaction bone grafting of the acetabulum using a mix of bone chips and $80 \% \mathrm{TCP} / 20 \% \mathrm{HA}$ [16]. In an in vitro study, Bolder reported that impaction bone grafting using TCP/HA and human bone chips significantly decreased socket migration in comparison with the use of human bone chips alone [19]. Aulakh et al. reported that the 13-year survival rate in revision THA with impaction bone grafting using a 


\begin{tabular}{|c|c|c|c|c|c|c|c|c|}
\hline \multirow{2}{*}{$\begin{array}{l}\text { AAOS } \\
\text { classification }\end{array}$} & \multicolumn{2}{|c|}{$\beta$-TCP } & \multicolumn{2}{|c|}{ HA } & \multicolumn{2}{|c|}{ Bulk allograft } & \multirow[t]{2}{*}{ total } & \multirow{2}{*}{$\begin{array}{l}\text { survival } \\
\text { rate }\end{array}$} \\
\hline & stable & failure & stable & failure & stable & failure & & \\
\hline II & 3 & 0 & 2 & 0 & 1 & 0 & 6 & $100 \%$ \\
\hline III & 20 & 8 & 19 & 2 & 16 & 1 & 66 & $83.3 \%$ \\
\hline IV & 0 & 0 & 1 & 3 & 1 & 0 & 5 & $40 \%$ \\
\hline total & 23 & 8 & 22 & 5 & 18 & 1 & 77 & $81.6 \%$ \\
\hline $\begin{array}{l}\text { survival } \\
\text { rate } \\
\text { (mean follow- } \\
\text { up duration) }\end{array}$ & \multicolumn{2}{|c|}{$\begin{array}{c}74.2 \% \\
(8.9 \pm 5.0)\end{array}$} & \multicolumn{2}{|c|}{$\begin{array}{c}81.5 \% \\
(8.3 \pm 2.3)\end{array}$} & \multicolumn{2}{|c|}{$\begin{array}{c}94.7 \% \\
(5.1 \pm 2.5)\end{array}$} & & \\
\hline
\end{tabular}

Fig. 5 Number of radiographic failure cases according to type of bone graft and AAOS classification. AAOS: American Academy of Orthopaedic Surgeons, $\beta$-TCP: beta-tricalcium phosphate, HA: hydroxyapatite

mix of $50 \% \mathrm{HA}$ and $50 \%$ bone chips was $82 \%$, and $84 \%$ with impaction bone grafting using only bone chips [20]. There was no significant difference between the two groups [20]. Tanaka et al. reported a 5-year survival rate of $100 \%$ in THA using a KT plate with HA granules [19].

Many good outcomes accompanied acetabular reconstructions of revision THA using artificial bone grafts [16, 19-21]. Kawanabe et al. compared the outcomes of morselized allografts and bulk allografts, and found the 10-year survival rate was 53\% for morselized allografts and $82 \%$ for bulk grafts [9]. The authors also found the failure rate in the morselized allograft group was significantly higher than in the bulk allograft group when the acetabular defect was large (i.e., AAOS type III/IV) [9]. Based on our observations, the survival curves were significantly different between the $\beta$-TCP group and bulk allograft

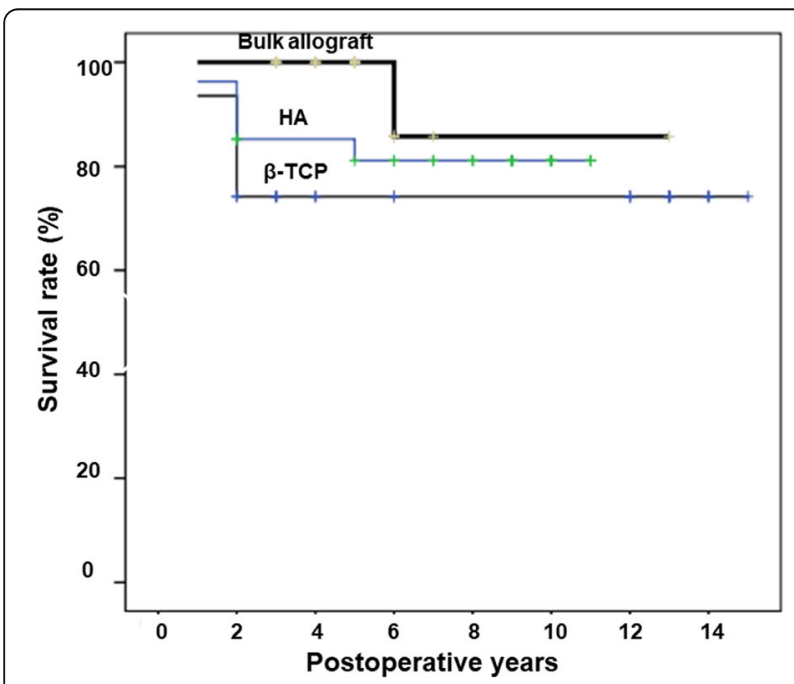

Fig. 6 A Kaplan-Meier survival curve with radiographic failure as the endpoint. $\beta$-TCP: beta-tricalcium phosphate, HA: hydroxyapatite group. These results indicate the type of bone graft may affect radiographic survival rate when using a KT plate.

We further evaluated risk factors for failure of revision THA in association with clinical factors (age at the time of the operation, preoperative JOA score, postoperative JOA score, BMI at final follow-up assessment, follow-up duration, and UCLA activity score at final follow-up assessment), type of bone graft ( $\beta$-TCP, HA, bulk allograft), and AAOS bone defect classifications. Only AAOS type IV was found to be a significant risk factor for failure of revision THA. Based on this finding, bone defect size is the critical risk factor for failure of revision THA using a KT plate.

Other reconstruction devices can fix the posterior wall in the case of massive host bone defect $[20,21]$. Rogers et al. reported that an ilioischial cage or cup cage was able to fix the device to both the superior and inferior host bone with screws [20]. Friedrich et al. reported reconstruction for pelvic discontinuity using a patient-specific custom-made implant [21]. We are not aware of any reports of posterior plating combined with the use of a KT plate for pelvic discontinuity. Nonetheless, posterior plating might improve the survival rate of revision surgery with a $\mathrm{KT}$ plate in pelvic discontinuity.

A major limitation of this study is its small cohort size for statistical analysis. However, the number of hips evaluated in the study was quite high in comparison with other clinical studies of acetabular revision surgery $[9-11,19]$. Another limitation is that three types of bone grafts were used at different times. Further, the mean follow-up duration was longer in the $\beta$-TCP group (mean: $8.9 \pm 5.0 \mathrm{y}$ ) and HA group (mean: $8.3 \pm 2.3$ y) compared to the bulk allograft group (mean: $5.1 \pm 2.5 \mathrm{y}$ ). These limitations may affect the survival result. 


\section{Conclusion}

The midterm outcomes of revision THA indicate that type of bone graft and bone defect size may affect radiographic survival rate when using a $\mathrm{KT}$ plate. New devices and techniques for KT plates are needed to improve the treatment of pelvic discontinuity.

\section{Abbreviations}

B-TCP: beta-tricalcium phosphate; AAOS: American Academy of Orthopaedic Surgeons; BMI: Body mass index; HA: Hydroxyapatite; JOA: Japanese Orthopaedic Association; OR: Odds ratio; THA: Total hip arthroplasty; UCLA: University of California, Los Angeles

\section{Acknowledgements}

Not applicable.

\section{Funding}

The authors have no funding.

\section{Availability of data and materials}

Data sharing not applicable to this article as no datasets were generated or analyzed during the current study.

\section{Authors' contributions}

SHay participated in the study design, drafting of the manuscript, and data collection. TN participated in the data collection and drafting of the manuscript. SHas carried out data collection and drafting of the manuscript. TM participated in the data collection and drafting of the manuscript. KT participated in the study design and helped to revise the manuscript. $\mathrm{KI}$ participated in the data collection and drafting of the manuscript. KN carried out data collection and drafting of the manuscript. RK participated in the study design and helped to revise the manuscript. All authors read and approved the final manuscript.

\section{Ethics approval and consent to participate}

This study is a retrospective review of patient records. The study protocol was approved by Kobe University Graduate School of Medicine Ethics Committee on September 8, 2011 (No 1220), and informed consent for participation in the study was obtained from all participants.

\section{Consent for publication}

Not applicable.

\section{Competing interests}

The authors declare that they have no competing interests.

\section{Publisher's Note}

Springer Nature remains neutral with regard to jurisdictional claims in published maps and institutional affiliations.

\section{Author details}

'Department of Orthopaedic Surgery, Kobe University Graduate School of Medicine, 7-5-1 Kusunoki-cho, Chuo-ku, Kobe 650-0017, Japan. ${ }^{2}$ Department of Orthopaedic Surgery, Kakogawa City Hospital, Kakogawa, Japan.

${ }^{3}$ Department of Orthopaedic Surgery, Kobe Kaisei Hospital, Kobe, Japan.

Received: 30 May 2017 Accepted: 28 August 2017

Published online: 02 September 2017

\section{References}

1. Caton J, Prudhon JL. Over 25 years survival after Charnley's total hip arthroplasty. Int Orthop. 2011;35(2):185-8.

2. Aldinger PR, Jung AW, Breusch SJ, Ewerbeck V, Parsch D. Survival of the cementless Spotorno stem in the second decade. Clin Orthop Relat Res. 2009:467(9):2297-304

3. Suckel A, Geiger F, Kinzl L, Wulker N, Garbrecht M. Long-term results for the uncemented Zweymuller/Alloclassic hip endoprosthesis. A 15-year minimum follow-up of 320 hip operations. J Arthroplast. 2009;24(6):846-53.
4. Boscainos PJ, Kellett CF, Maury AC, Backstein D, Gross AE. Management of periacetabular bone loss in revision hip arthroplasty. Clin Orthop Relat Res. 2007;465:159-65.

5. Ilyas I, Alrumaih HA, Kashif S, Rabbani SA, Faqihi AH. Revision of Type III and Type IVB Acetabular defects with Burch-Schneider Anti-Protrusio Cages. J Arthroplast. 2015;30(2):259-64.

6. Schlegel UJ, Bitsch RG, Pritsch M, Clauss M, Mau H, Breusch SJ. Mueller reinforcement rings in acetabular revision: outcome in 164 hips followed for 2-17 years. Acta Orthop. 2006;77(2):234-41.

7. Gerber A, Pisan M, Zurakowski D, Isler B. Ganz reinforcement ring for reconstruction of acetabular defects in revision total hip arthroplasty. J Bone Joint Surg Am. 2003;85-A(12):2358-64

8. Kerboull M, Hamadouche M, Kerboull L. The Kerboull acetabula reinforcement device in major acetabular reconstructions. Clin Orthop Relat Res. 2000:378(9):155-68.

9. Kawanabe K, Akiyama H, Onishi E, Nakamura T. Revision total hip replacement using the Kerboull acetabular reinforcement device with morsellised or bulk graft: results at a mean follow-up of 8.7 years. J Bone Joint Surg Br Vol. 2007:89(1):26-31.

10. Baba T, Shitoto K. Revision of total hip arthroplasty using the Kerboull and KT plates. Int Orthop. 2010;34(3):341-7.

11. Hori J, Yasunaga Y, Yamasaki T, Yoshida T, Oshima S, Yamasaki K, Matsuo T, Ochi M. Mid-term results of acetabular reconstruction using a Kerboull-type acetabular reinforcement device. Int Orthop. 2012;36(1):23-6.

12. Kawanabe K, Akiyama H, Goto K, Maeno S, Nakamura T. Load dispersion effects of acetabular reinforcement devices used in revision total hip arthroplasty: a simulation study using finite element analysis. J Arthroplast. 2011;26(7):1061-6.

13. McNamara I, Deshpande S, Porteous M. Impaction grafting of the acetabulum with a mixture of frozen, ground irradiated bone graft and porous synthetic bone substitute (Apapore 60). J Bone Joint Surg Br Vol. 2010;92(5):617-23.

14. Oonishi $H$, Iwaki Y, Kin N, Kushitani S, Murata N, Wakitani S, Imoto K. Hydroxyapatite in revision of total hip replacements with massive acetabular defects: 4- to 10-year clinical results. J Bone Joint Surg Br Vol. 1997;79(1):87-92

15. Schwartz $C$, Liss $P$, Jacquemaire $B$, Lecestre $P$, Frayssinet $P$. Biphasic synthetic bone substitute use in orthopaedic and trauma surgery: clinical, radiological and histological results. J Mater Sci Mater Med. 1999:10(12):821-5.

16. Blom AW, Wylde V, Livesey C, Whitehouse MR, Eastaugh-Waring S, Bannister GC, Learmonth ID. Impaction bone grafting of the acetabulum at hip revision using a mix of bone chips and a biphasic porous ceramic bone graft substitute. Acta Orthop. 2009;80(2):150-4.

17. Hasegawa Y, Iwata H, Mizuno M, Genda E, Sato S, Miura T. The natura course of osteoarthritis of the hip due to subluxation or acetabular dysplasia. Arch Orthop Trauma Surg. 1992;111(4):187-91.

18. DeLee JG, Charnley J. Radiological demarcation of cemented sockets in total hip replacement. Clin Orthop Relat Res. 1976;121(11):20-32.

19. Tanaka C, Shikata J, Ikenaga M, Takahashi M. Acetabular reconstruction using a Kerboull-type acetabular reinforcement device and hydroxyapatite granules: a 3- to 8-year follow-up study. J Arthroplast. 2003;18(6):719-25.

20. Rogers BA, Whittingham-Jones PM, Mitchell PA, Safir OA, Bircher MD, Gross AE. The reconstruction of periprosthetic pelvic discontinuity. J Arthroplast. 2012;27(8):1499-506. e1491

21. Friedrich MJ, Schmolders J, Michel RD, Randau TM, Wimmer MD, Kohlhof H, Wirtz DC, Gravius S. Management of severe periacetabular bone loss combined with pelvic discontinuity in revision hip arthroplasty. Int Orthop. 2014;38(12):2455-61. 